\title{
Eficiência de gongocompostos obtidos a partir de diferentes resíduos vegetais e sistemas de produção no desenvolvimento de mudas de alface
}

\author{
Luiz Fernando de Sousa ANTUNES ${ }^{1}$, Rafael Girelli de SOUZA', Julia de Lima KRAHENBUHL ${ }^{2}$, \\ Guilherme Rocha DIAS², Dione Galvão da SILVA 3 , Maria Elizabeth Fernandes CORREIA ${ }^{3}$

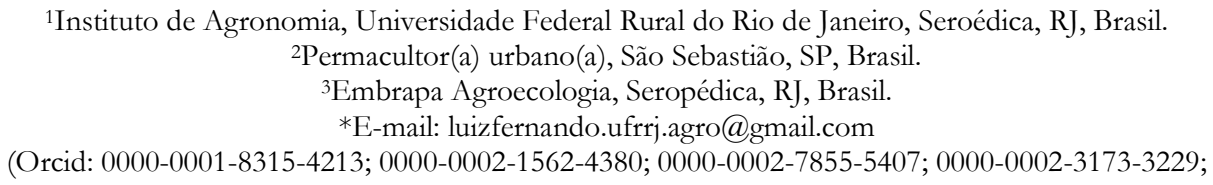
0000-0002-2310-1854; 0000-0003-1919-6659)

Recebido em 29/11/2019; Aceito em 23/02/2021; Publicado em 23/04/2021.

\begin{abstract}
RESUMO: O uso do gongocomposto pode contribuir para suprir a crescente demanda por substratos destinados à produção de mudas de hortaliças em ambientes rurais e urbanos. Nesse contexto, objetivou-se com este trabalho verificar a eficiência dos gongocompostos obtidos em dois diferentes sistemas de produção, situados em regiões de ambientes distintos (estados do RJ e SP) e com a utilização de resíduos orgânicos e espécies de diplópodes diferentes entre si, na produção de mudas de alface. Inicialmente foi realizada uma minuciosa caracterização dos substratos avaliados, caracterizando as propriedades físicas, físico-químicas e químicas. O desempenho dos diferentes substratos na produção de mudas de alface foi avaliado por meio da semeadura de alface crespa cultivar Grand Rapids em bandejas de poliestireno expandido de 200 células. As mudas foram avaliadas aos 30 dias após a semeadura. Os gongocompostos produzidos no estado do RJ e SP apresentam diferenças em suas propriedades físicas, físico-químicas e químicas. No entanto, ambos produziram mudas de alface com qualidade semelhante, cujos parâmetros fitotécnicos foram superiores ao substrato comercial. Pode-se concluir que ambos os gongocompostos são eficientes como substrato na produção de mudas de alface, os quais podem ser produzidos em ambientes rurais e urbanos, atendendo à necessidade atual por insumos agrícolas sustentáveis.
\end{abstract}

Palavras-chave: resíduos agrícolas e urbanos; diplópodes; gongocompostagem; substratos orgânicos; horticultura.

\section{Efficiency of millicomposts obtained from different vegetable residues and production systems in the development of lettuce seedlings}

\begin{abstract}
The use of millicompost can contribute to the growing demand for substrates for vegetable seedling production in rural and urban environments. In this context, the objective of this work was to verify the efficiency of millicomposts obtained in two different production systems, located in regions of different environments (states of RJ and SP) and with the use of organic residues and different species of diplopods, in the production of lettuce seedlings. Initially, a thorough characterization of the evaluated substrates was performed, characterizing the physical, physicochemical and chemical properties. The performance of different substrates in the production of lettuce seedlings was evaluated by sowing crisp lettuce cultivar Grand Rapids in 200-cell expanded polystyrene trays. The seedlings were evaluated at 30 days after sowing. Millicomposts produced in the states of RJ and SP show differences in their physical, physicochemical and chemical properties. However, both produced similar quality lettuce seedlings, whose phytotechnical parameters were superior to the commercial substrate. It can be concluded that both millicomposts are efficient as a substrate in the production of lettuce seedlings, which can be produced in rural and urban environments, meeting the current need for sustainable agricultural inputs.

Keywords: agricultural and urban wastes; diplopods; millicomposting; organic substrates; horticulture.
\end{abstract}

\section{INTRODUÇÃO}

As hortaliças estão diariamente na mesa dos brasileiros. Entre as folhosas, a alface (Lactuca sativa L.) é a preferida e mais consumida no país devido ao seu sabor e valor nutricional, sendo fonte de fibras, vitaminas e sais minerais, que são conservados pois a mesma é predominantemente consumida in natura nas saladas ou em lanches (MAIA, 2019).

A alface pertence à família das Asteráceas, tendo como provável centro de origem as regiões amenas do Mediterrâneo (FIORINI et al., 2016). É uma planta de ciclo curto e possibilita sua produção durante o ano todo, a depender do clima da região e cultivar utilizada, garantindo um rápido retorno financeiro ao produtor (MILHOMENS et al., 2015). Os solos mais adequados para o seu cultivo são os de textura média, com boa capacidade de retenção de água e valores de $\mathrm{pH}$ entre 6,0 a 6,8 , facilitando o desenvolvimento radicular e a absorção de nutrientes. A temperatura ideal varia de 12 a $22^{\circ} \mathrm{C}$, para boa produção de folhas e cabeças (FILGUEIRA, 2008).

De acordo com o Censo Agropecuário de 2017, a produção brasileira de alface no período de referência 20162017 foi de 908.186 toneladas, das quais 65,19\% foram 
produzidas na região Sudeste, seguida pelas produções das regiões: Sul com 12,87\%, Centro-Oeste com 10,95\%, Nordeste com 8,21\% e Norte com 2,77\% (IBGE, 2017).

Devido as características como a praticidade no cultivo, ciclo rápido, boa produtividade e com amplo mercado consumidor, a alface é uma cultura de importância econômica considerável, já que a utilização de fácil manejo e sem necessidade de uma tecnologia mais rebuscada são elementos que fazem da cultura um dos carros chefe da agricultura familiar (BARROS et al., 2016).

Para se alcançar máximo potencial produtivo da cultura, a qualidade das mudas é de fundamental importância, onde a mesma só será obtida quando se utilizar um substrato capaz de suprir todas as necessidades da planta enquanto muda (ANTUNES et al., 2018).

O substrato deve apresentar propriedades físicas (umidade, macroporos e microporos), físico-químicas (condutividade elétrica e $\mathrm{pH}$ ), químicas (nutrientes e capacidade de troca catiônica) e biológicas (ausência de patógenos) (NADAI et al., 2015), garantindo a obtenção de mudas com qualidade superior, as quais exibirão quando transplantadas ao campo, elevados índices de pegamento, graças à formação de raízes robustas e torrão íntegro, permitindo a formação de estandes mais uniformes e ganhos na produtividade final (ANTUNES et al., 2018).

No mercado existem diversos tipos de substratos comerciais, sendo eles provenientes de fontes minerais, organominerais ou orgânicas (ANTUNES et al., 2019a). Sabe-se também que o custo do substrato para produção de mudas, impacta diretamente no valor final da produção (SANTOS et al., 2018). Deste modo, a utilização de resíduos orgânicos gerados ao longo da cadeia produtiva, com a finalidade de se obter um substrato de qualidade e baixo custo, pode ser uma excelente opção para reduzir esses custos, maximizando o lucro do produtor e contribuindo no aumento da qualidade do vegetal (CORREA et al., 2019).

Ainda pouco conhecida e difundida no meio científico e entre os produtores de hortaliças rurais e urbanos, a gongocompostagem tem se mostrado como uma biotecnologia alternativa, viável e rentável, que visa oferecer ao agricultor uma nova opção de reaproveitamento de seus resíduos orgânicos, aprimorando a ciclagem dos nutrientes dentro da propriedade, além de proporcionar economia, dispensando a aquisição de substratos comerciais.

A gongocompostagem consiste em um processo diferente da compostagem clássica, não exibindo durante a transformação dos resíduos a elevação de temperatura, pois através da atividade biológica dos diplópodes, organismos decompositores da fauna do solo (conhecidos como gongolos ou piolhos-de-cobra), ocorre a fragmentação dos resíduos lignocelulósicos de relações $\mathrm{C} / \mathrm{N}$ superiores a $30 \mathrm{em}$ partes menores, o que aumenta suas superfícies específicas, resultando na obtenção de gongocompostos estáveis entre 120 e 180 dias (ANTUNES, 2017; ANTUNES et al., 2019b).

As pesquisas na área da gongocompostagem ainda são bem pontuais no mundo, sendo desenvolvidas na Índia e no Brasil, apenas. Os indianos verificaram que o gongocomposto proporcionou melhores performances na produção de pimenta vermelha em vaso (RAMANATHAN; ALAGESAN, 2012) e Senthilkumar et al. (2018) observaram uma melhor germinação das sementes e crescimento das mudas de cinco diferentes espécies florestais. No Brasil os resultados também confirmam a qualidade do gongocomposto como substrato orgânico, possibilitando a obtenção de mudas de hortaliças e ornamentais de qualidade (ANTUNES et al., 2018; ANTUNES et al., 2019a).

Nesse contexto, objetivou-se com este trabalho caracterizar as propriedades físicas, físico-químicas e químicas dos gongocompostos produzidos em dois diferentes sistemas de produção, situados em regiões de ambientes distintos e com a utilização de resíduos orgânicos e espécies de diplópodes diferentes. Posteriormente, verificou-se a eficiência dos gongocompostos obtidos nas diferentes áreas através da produção de mudas de alface em bandejas de poliestireno expandido.

\section{MATERIAL E MÉTODOS}

\subsection{Produção do gongocomposto no município de} Seropédica - RJ

A gongocompostagem foi conduzida na área experimental do Sistema Integrado de Produção Agroecológica - SIPA, localizado na Fazendinha $\mathrm{Km} \mathrm{47,}$ Seropédica-RJ, no período de março a agosto de 2017. O clima da região é do tipo Aw, segundo a classificação de Köppen, com chuvas concentradas entre novembro e março, temperatura média anual de $23,9{ }^{\circ} \mathrm{C}$ e precipitação anual média de $1.213 \mathrm{~mm}$ (OLVEIRA JÚNIOR et al., 2014)

Foram utilizados anéis de concreto, com altura de $0,5 \mathrm{~m}$ e largura de $1 \mathrm{~m}$, com capacidade para receber 400 litros de resíduos (Figura 1-A). Na primeira etapa, os resíduos foram quantificados e depositados no interior dos três anéis, a uma altura de aproximadamente 40 centímetros. O processo de gongocompostagem foi realizado a partir da mistura de resíduos de Baubinia sp. (folhas de pata-de-vaca), Paspalum notatum (aparas de grama), Musa sp. (folhas de bananeira) e papelão picado (pedaços $\leq 5 \mathrm{~cm}$ ), cujas proporções dos materiais foram de 180 litros, 135 litros, 90 litros e 45 litros para cada resíduo, respectivamente. Logo após foram molhados e misturados a fim de se obter homogeneidade. (Figura 1-B).

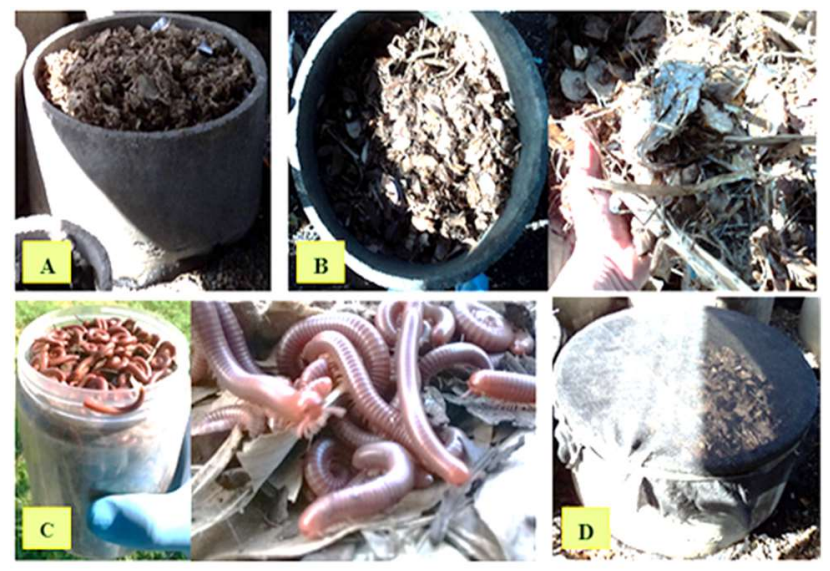

Figura 1. Anel de concreto com adição de 400 litros de resíduos (A); resíduos devidamente preparados para a gongocompostagem (B); quantificação e adição dos gongolos nos anéis contendo os resíduos (C); Início do processo de gongocompostagem e proteção dos anéis (D).

Figure 1. Concrete ring with addition of 500 liters of waste (A); wastes properly prepared for gong composting (B); quantification and addition of gongols in rings containing residues (C); beginning of the gong-composting process and protection of the rings (D).

$\mathrm{Na}$ segunda etapa, cada anel recebeu uma quantidade aproximada de 2,2 litros de diplópodes da espécie Trigoniulus corallinus, que equivale a uma população de aproximadamente 
3.960 indivíduos adultos (Figura 1-C), os quais foram coletados manualmente em canteiros de minhocultura, em composteiras e em gramado contendo aparas recentes.

Os anéis foram cobertos com sombrite para impedir que os gongolos fugissem ao subir pela parede do anel ou ainda impedir a entrada de algo indesejado no anel, o que poderia prejudicar o processo de gongocompostagem (Figura 1-D).

Houve a necessidade de observar a umidade do material contido nos anéis durante todo o processo, sendo que a manutenção desta umidade foi realizada com adição de água via regador (aproximadamente quatro litros por anel de concreto) semanalmente ou quando necessário, para mantêla em torno de $50-60 \%$, de modo a manter o ambiente estivesse propício à sobrevivência dos gongolos, preservando a continuidade do processo de compostagem.

O gongocomposto foi obtido aos 180 dias após o início de todo processo supracitado, através do peneiramento em malha de $2 \mathrm{~mm}$ (Figura 2) e posteriormente armazenado em sacos plásticos, até que houvesse sua destinação à produção de mudas de hortaliças.
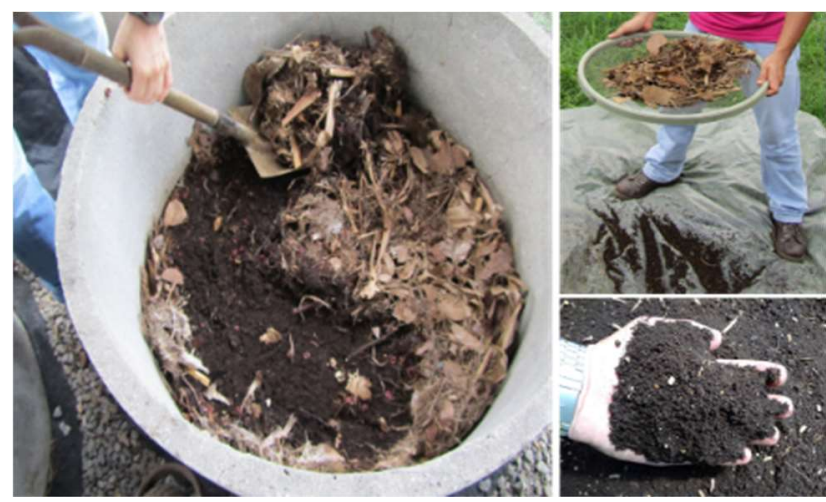

Figura 2. Processo de retirada e peneiramento do gongocomposto obtido aos 180 dias, produzido a partir de folhas de pata-de-vaca, aparas de grama, folhas de bananeira e papelão picado.

Figure 2. Process of removal and sieving of millicompost obtained at 180 days, produced from Bauhinia sp. leaves, grass clippings, Musa sp. leaves and shredded cardboard.

\subsection{Produção do gongocomposto no município de São Sebastião - SP}

A gongocompostagem foi realizada em uma propriedade urbana no bairro de Boiçucanga, na cidade de São Sebastião - SP, litoral norte do estado de São Paulo. O clima da região é do tipo Am, segundo a classificação de Köppen, sendo caracterizado como tropical com chuvas excessivas e inverno seco, temperatura média anual de $24,8^{\circ} \mathrm{C}$ e precipitação anual média de $1.507 \mathrm{~mm}$ (MILANESI, 2016).

O processo de gongocompostagem adotado na propriedade urbana é conduzido pelos permacultores urbanos Guilherme Rocha Dias e Julia de Lima Krahenbuhl, os quais adaptaram a metodologia da pesquisa estabelecida na Embrapa Agrobiologia. Este processo é dividido em três etapas: a pré-compostagem, compreendida pelas etapas 1 e 2, durando entre 20 e 30 dias.

A primeira etapa compreende a chegada dos resíduos na propriedade, onde são triturados e posteriormente depositados em baias para organizar o processo de compostagem. Os resíduos utilizados no processo são provenientes de podas urbanas, existindo grande diversidade local, mas variando predominantemente entre Musa sp. (folhas de bananeira), Heliconia sp. (folhas de heliconia), Alpinia purpurata (folhas de alpinia), Hedychium coronarium (lírio do brejo) e Malvaviscus arboreus (hibiscos). Na segunda etapa os resíduos são transferidos para uma segunda baia, devidamente coberta para protegê-los da chuva. Nessa fase o volume dos resíduos está bem reduzido devido ao próprio processo de compostagem iniciado e à perda de umidade. $\mathrm{Na}$ terceira etapa ocorre o processo controlado de gongocompostagem, onde os resíduos provenientes das fases anterior (Figura 3-A) são acondicionados nas caixas plásticas de 60 L (Figura 3-B).

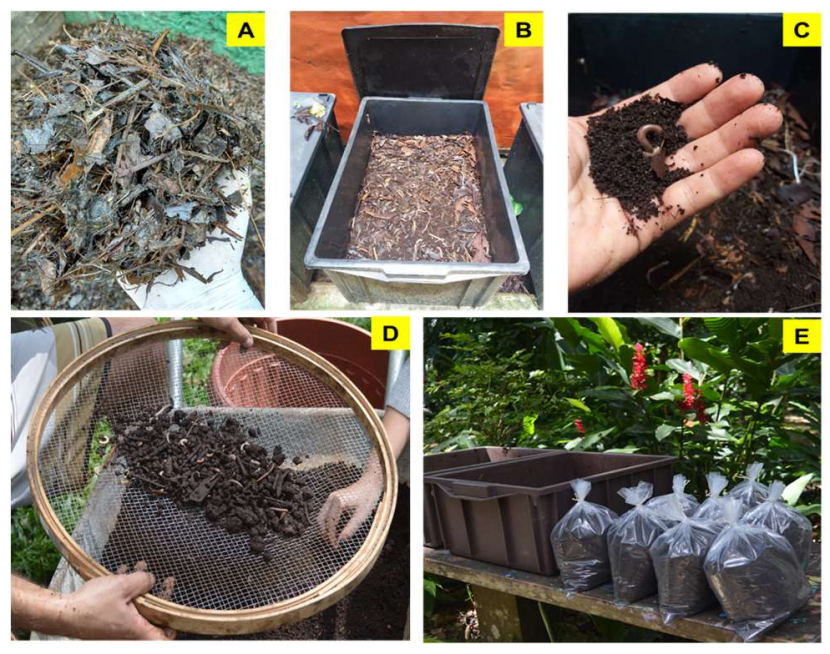

Figura 3. Resíduos de poda urbana pré-compostados (A); caixa com capacidade de 60 litros de resíduos para gongocompostagem (B); gongocomposto e gongolo da espécie Rhinocricus padbergi (C); peneiramento do gongocomposto e retenção dos gongolos após cerca de 45 dias de gongocompostagem (D); gongocomposto ensacado e pronto para ser comercializado na região $(\mathrm{E})$.

Figure 3. Precomposted urban pruning wastes (A); box with a capacity of 60 liters of wastes for millicomposting (B); millicompost and millipede of the species Rhinocricus padbergi (C); millicompost sievied and retention of millipedes after about 45 days of millicomposting (D); millicompost bagged and ready to be marketed in the region $(\mathrm{E})$.

Os diplópodes utilizados no processo são nativos do ambiente de Mata Atlântica e pertencem a espécie Rhinocricus padbergi. Eles são adicionados nas caixas e/ou recolocados após o processo de peneiramento do material já compostado (Figuras 3-C e 3-D). A quantidade utilizada em cada caixa é de aproximadamente $0,2 \mathrm{~L}, \quad \mathrm{o}$ que equivale a aproximadamente 350 indivíduos adultos. Todo o processamento dos resíduos até a obtenção do gongocomposto dura cerca de 80 a 120 dias (Figura 3-E).

\subsection{Caracterização das propriedades físicas, físico- químicas e químicas do gongocomposto}

As propriedades físicas avaliadas foram as seguintes: macroporosidade, microporosidade, porosidade total, capacidade de retenção de água a $10 \mathrm{~cm}$ de coluna d'água e densidade volumétrica, obtidas pelo método da mesa de tensão, utilizando anéis metálicos de $100 \mathrm{~mL}$ e tensão de 60 $\mathrm{cm}$ de coluna d'água (BRASIL, 2008; TEIXEIRA et al., 2017).

As análises de $\mathrm{pH}$ foram realizadas em solução de água destilada $(5: 1 \mathrm{v} / \mathrm{v})$ e a condutividade elétrica foi determinada no mesmo extrato aquoso obtido para a medição do $\mathrm{pH}$, de acordo com o método descrito por BRASIL (2008). Vale ressaltar que foram feitas três repetições para todos os parâmetros avaliados. Os teores totais de N, P, K, Ca e Mg 
dos substratos foram analisados e fornecidos pelo laboratório da Embrapa Agrobiologia por meio de digestão das amostras (TEIXEIRA et al., 2017).

\subsection{Produção das mudas de alface}

O experimento foi conduzido em casa de vegetação do Sistema Integrado de Produção Agroecológica - SIPA, localizado na Fazendinha Km 47, Seropédica-RJ, no período de 01 a 30 de setembro de 2017.

Foram utilizadas bandejas de poliestireno expandido de 200 células para realizar a semeadura de alface do tipo crespa cultivar Grand Rapids TBR da marca ISLA, colocando de duas a três sementes por célula.

Os tratamentos consistiram de três substratos orgânicos: 1) Gongocomposto, produzido em Seropédica, conforme descrito no item 2.1; 2) Gongocomposto produzido em São Sebastião, conforme descrito no item 2.2; 3) Substrato

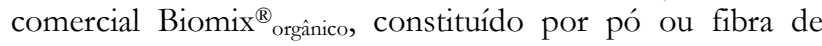
coco, casca de pinus moída e compostada, Bokashi (aditivo orgânico com macro e micronutrientes) e composto orgânico fórmula Biomix ${ }^{\circledR}$, tido como controle.

Aos sete dias após a semeadura, realizou-se o desbaste na bandeja, mantendo apenas uma planta por célula. Aos 30 dias após a semeadura, retirou-se de forma aleatória dez mudas de alface por unidade experimental (bandeja) e foram avaliados os seguintes parâmetros fitotécnicos: massa fresca da parte aérea (MFPA), massa seca da parte aérea (MSPA), massa fresca de raízes (MFR), massa seca de raízes (MSR), altura da planta (AP), número de folhas $(\mathrm{NF})$, vigor da muda $(\mathrm{VM})$ e a estabilidade do torrão (ET). Após a pesagem da massa fresca da parte aérea e das raízes, essas foram separadas individualmente em sacos de papel e mantidas em estufa de circulação de ar forçada a $65^{\circ} \mathrm{C}$ por 72 horas, afim de se determinar a massa seca das mesmas.

O vigor das mudas (VM) foi determinado através da metodologia adaptada de Franzin et al. (2005), classificando como: Nota 1: ótimo vigor, número de folhas $\geq 4$, altura maior que $5 \mathrm{~cm}$ e ausência visual de deficiência nutricional; Nota 2: vigor bom, número de folhas $\geq 4$, altura $\geq 5 \mathrm{~cm} \mathrm{e}$ início de amarelado não proeminente nas folhas basais; Nota 3: vigor regular, número de folhas $\geq 4$, altura $\geq 5 \mathrm{~cm}$; deficiência nutricional expressa por um amarelecimento proeminente que se estende para além das folhas basais ou outro sintoma intrínseco; Nota 4: vigor ruim, deficiência nutricional bem destacada, expressa por problemas na altura ( $\leq 5 \mathrm{~cm}$ ), número de folhas reduzido $(\leq 4$ folhas) e amarelecimento intenso ou outro sintoma intrínseco.
A estabilidade do torrão (ET) foi determinada por uma metodologia adaptada de Gruszynski (2002), classificando como: Nota 1: Baixa estabilidade, $50 \%$ ou mais do torrão fica retido no recipiente na retirada da muda e o torrão não permanece coeso; Nota 2: Entre 30 a $50 \%$ do torrão fica retido no recipiente na retirada da muda, porém o torrão não permanece coeso; Nota 3: Regular, entre 15 a 30\% do torrão fica retido no recipiente na retirada da muda, porém não permanece coeso; Nota 4: Boa estabilidade, o torrão é destacado completamente do recipiente com até 90\% de coesão e perda máxima de até $10 \%$ do substrato.

\subsection{Análises estatísticas}

O delineamento experimental utilizado foi o inteiramente casualizado, com três tratamentos (substratos) e quatro repetições (bandejas) para cada tratamento.

Para a análise dos dados foi realizada a avaliação da homogeneidade das variâncias dos erros pelo teste de Bartlett e da normalidade pelo teste de Shapiro-Wilk. Os dados foram submetidos à análise de variância, com a aplicação do teste $\mathrm{F}$ e posteriormente submetidos ao teste de Tukey $(\mathrm{p} \leq 0,05) \mathrm{com}$ o auxílio do programa livre RBio (BHERING, 2017).

\section{RESULTADOS}

\subsection{Propriedades físicas dos substratos}

As características físicas dos substratos foram analisadas e seguem apresentadas na Tabela 1 . Os percentuais de macroporos presentes em todos os substratos foram semelhantes, não havendo diferença significativa $O$ Gongocomposto RJ apresentou maior microporosidade que os substratos Gongocomposto SP e Biomix ${ }^{\circledR}$. Já a porosidade total não diferiu entre os gongocompostos, os quais exibiram percentuais superiores ao substrato comercial $(16,89 \%$ e 13,67\% a mais para os Gongocompostos de RJ e SP, respectivamente).

A capacidade de retenção de água seguiu o mesmo padrão que a microporosidade, sendo que o Gongocomposto RJ exibiu percentuais superiores aos demais substratos na capacidade de reter água à uma altura de 10 centímetros de coluna d'água.

Já a densidade volumétrica seguiu o inverso, onde o substrato Biomix $^{\circledR}$ foi $16 \%$ mais denso que o Gongocomposto SP e 52,63\% mais denso que o Gongocomposto RJ.

Tabela 1. Análises físicas dos substratos orgânicos utilizados na produção de mudas de alface crespa cv. Grand Rapids: percentuais de macroporosidade, microporosidade, porosidade total, capacidade de retenção de água à tensão de $10 \mathrm{~cm}\left(\mathrm{CRA}_{10} \mathrm{~cm}\right)$ e densidade volumétrica. Table 1. Physical analyzes of organic substrates used in the production of curly lettuce seedlings cv. Grand Rapids: percent macroporosity, microporosity, total porosity, water holding capacity at $10 \mathrm{~cm}$ tension $\left(\mathrm{CRA}_{10} \mathrm{~cm}\right)$ and volumetric density.

\begin{tabular}{|c|c|c|c|c|c|}
\hline \multirow{2}{*}{ Substratos } & Macroporos & Microporos & Porosidade total & \multirow{2}{*}{$\begin{array}{l}\mathrm{CRA}_{10 \mathrm{~cm}} \\
\mathrm{~mL} 50 \mathrm{~cm}^{-3}\end{array}$} & \multirow{2}{*}{$\begin{array}{l}\text { Densidade volumétrica } \\
\qquad\left(\mathrm{kg} \mathrm{m}^{-3}\right)\end{array}$} \\
\hline & \multicolumn{3}{|c|}{ - } & & \\
\hline Gongocomposto RJ & $18,67 \mathrm{a}$ & $73,44 \mathrm{a}$ & $92,11 \mathrm{a}$ & $36,72 \mathrm{a}$ & $190 \mathrm{c}$ \\
\hline Gongocomposto SP & $21,94 \mathrm{a}$ & $67,63 \mathrm{~b}$ & $89,57 \mathrm{a}$ & $33,82 \mathrm{~b}$ & $250 \mathrm{~b}$ \\
\hline Biomix ${ }^{\mathbb{R}}$ orgânico & $18,34 \mathrm{a}$ & $60,46 \mathrm{c}$ & $78,80 \mathrm{~b}$ & $30,23 \mathrm{c}$ & $290 \mathrm{a}$ \\
\hline $\mathrm{CV}(\%)$ & 9,44 & 2,62 & 1,52 & 2,63 & 2,10 \\
\hline
\end{tabular}

Médias seguidas pela mesma letra na coluna não diferem pelo teste de Tukey $(\mathrm{p} \leq 0,05)$.

\subsection{Propriedades físico-químicas e químicas dos substratos}

As características físico-químicas dos substratos foram analisadas e estão presentes na Tabela 2. O valor de $\mathrm{pH}$ do
Gongocomposto RJ foi superior aos encontrados nos substratos Gongocomposto SP e Biomix ${ }^{\circledR}$. A condutividade elétrica (CE) não apresentou diferença entre os 
gongocompostos do RJ e SP, mas diferiram do substrato Biomix ${ }^{\circledR}$, cuja a condutividade foi $43,75 \%$ menor.

$\mathrm{O}$ valor da relação $\mathrm{C} / \mathrm{N}$ foi semelhante nos gongocompostos, mas foi superior a 20 no substrato Biomix ${ }^{\circledR}$ e conteúdo de carbono total presente neste substrato foi superior aos apresentados pelos gongocompostos.

Os teores totais dos macronutrientes $\mathrm{N}, \mathrm{P}, \mathrm{K}, \mathrm{Ca}$ e $\mathrm{Mg}$ dos substratos estão apresentados na Tabela 2. O Gongocomposto RJ apresentou as maiores médias para todos os teores de macronutrientes avaliados. Os teores de $\mathrm{P}$ e $\mathrm{Mg}$ não diferiram entre o Gongocomposto SP e substrato comercial Biomix ${ }^{\circledR}$, porém o Gongocomposto SP registrou teores superiores de $\mathrm{N}$ e $\mathrm{Ca}$, enquanto o Biomix ${ }^{\circledR}$ apenas foi superior a ele no conteúdo de $\mathrm{K}$.

\subsection{Avaliação dos parâmetros fitotécnicos das mudas de} alface

Os parâmetros fitotécnicos avaliados nas mudas de alface produzidas nos diferentes substratos orgânicos estão contidos na Tabela 3. As mudas produzidas nos diferentes gongocompostos apresentaram médias semelhantes no valor da massa fresca de parte aérea (MFPA), massa seca de parte aérea (MSPA), massa fresca de raiz (MFR), massa seca de raiz (MSR), altura de plantas (AP), número de folhas (NF) e vigor de mudas (VM). Entretanto se mostraram muito superiores às mudas obtidas com o uso do substrato Biomix ${ }^{\circledR}$ (Figura 3). O substrato comercial exibiu média superior apenas na estabilidade do torrão (ET), seguido pelo Gongocomposto RJ e de SP (Tabela 3).

Tabela 2. Análises do potencial hidrogeniônico $(\mathrm{pH})$, condutividade elétrica $(\mathrm{CE})$, relação $\mathrm{C} / \mathrm{N}$, conteúdo de carbono total e teores de macronutrientes totais dos substratos orgânicos utilizados na produção de mudas de alface crespa cv. Grand Rapids.

Table 2. Analysis of the hydrogenic potential $(\mathrm{pH})$, electrical conductivity (EC), C/N ratio, total carbon content and total macronutrient contents of organic substrates used in the production of curly lettuce cv. Grand rapids.

\begin{tabular}{|c|c|c|c|c|c|c|c|c|c|}
\hline \multirow{2}{*}{ Substratos } & \multirow{2}{*}{$\mathrm{pH}$} & \multirow{2}{*}{$\begin{array}{c}\mathrm{CE} \\
\left(\mathrm{dS} \mathrm{m}^{-1}\right)\end{array}$} & \multirow{2}{*}{$\begin{array}{c}\text { Relação } \\
\mathrm{C} / \mathrm{N}\end{array}$} & $\mathrm{C}$ & $\mathrm{N}$ & $\mathrm{P}$ & K & $\mathrm{Ca}$ & $\mathrm{Mg}$ \\
\hline & & & & \multicolumn{6}{|c|}{ - } \\
\hline Gongocomposto RJ & $7,34 \mathrm{a}$ & $0,68 \mathrm{a}$ & $15,23 \mathrm{~b}$ & $325,04 \mathrm{~b}$ & $23,26 \mathrm{a}$ & $2,96 \mathrm{a}$ & $4,78 \mathrm{a}$ & $31,69 \mathrm{a}$ & $4,48 \mathrm{a}$ \\
\hline Gongocomposto SP & $6,85 \mathrm{~b}$ & $0,69 \mathrm{a}$ & $14,60 \mathrm{~b}$ & $291,10 \mathrm{c}$ & $19,94 \mathrm{~b}$ & $1,63 \mathrm{~b}$ & $1,89 \mathrm{c}$ & $21,81 \mathrm{~b}$ & $3,04 \mathrm{~b}$ \\
\hline Biomix $^{\mathbb{R}}$ orgânico & $6,69 \mathrm{c}$ & $0,48 \mathrm{~b}$ & $41,92 \mathrm{a}$ & $354,34 \mathrm{a}$ & $7,75 \mathrm{c}$ & $1,53 \mathrm{~b}$ & $2,39 \mathrm{~b}$ & $9,03 \mathrm{c}$ & $2,73 \mathrm{~b}$ \\
\hline CV $(\%)$ & 0,85 & 2,88 & 2,02 & 3,12 & 3,71 & 6,99 & 2,97 & 7,86 & 6,46 \\
\hline
\end{tabular}

Médias seguidas pela mesma letra na coluna não diferem pelo teste de Tukey $(\mathrm{p} \leq 0,05)$.

Tabela 3. Valores médios da massa fresca de parte aérea (MFPA), massa seca de parte aérea (MSPA), massa fresca de raiz (MFR), massa seca de raiz (MSR), altura de plantas (AP), número de folhas (NF), vigor de mudas (VM) e estabilidade do torrão de mudas de alface crespa cv. Grand Rapids produzidas nos diferentes substratos orgânicos.

Table 3. Average values of shoot fresh weight, shoot dry weight, root fresh mass, root dry mass, plant height, number of leaves, seedling vigor and stability of the of curly lettuce cv. Grand rapids produced on different organic substrates.

\begin{tabular}{|c|c|c|c|c|c|c|c|c|}
\hline \multirow{2}{*}{ Substratos } & MFPA & MSPA & MFR & MSR & \multirow{2}{*}{$\begin{array}{l}\mathrm{AP} \\
(\mathrm{cm})\end{array}$} & \multirow{2}{*}{$\mathrm{NF}$} & \multirow{2}{*}{ VM } & \multirow{2}{*}{ ET } \\
\hline & \multicolumn{4}{|c|}{ mg planta ${ }^{-1}$} & & & & \\
\hline Gongocomposto RJ & $779,50 \mathrm{a}$ & $47,94 \mathrm{a}$ & $144,50 \mathrm{a}$ & $9,23 \mathrm{a}$ & $8,60 \mathrm{a}$ & $3,78 \mathrm{a}$ & $1,8 \mathrm{~b}$ & $1,95 \mathrm{ab}$ \\
\hline Gongocomposto SP & $740,50 \mathrm{a}$ & $44,83 \mathrm{a}$ & $130,00 \mathrm{a}$ & $9,70 \mathrm{a}$ & $8,82 \mathrm{a}$ & 3,88 a & $1,9 \mathrm{~b}$ & $1,78 \mathrm{~b}$ \\
\hline Biomix $^{\circledR}$ orgânico & $279,50 \mathrm{~b}$ & $24,36 \mathrm{~b}$ & $77,75 \mathrm{~b}$ & $6,97 \mathrm{~b}$ & $5,75 \mathrm{~b}$ & $3,30 \mathrm{~b}$ & $3,05 \mathrm{a}$ & $2,15 \mathrm{a}$ \\
\hline $\mathrm{CV}(\%)$ & 29,23 & 26,38 & 37,95 & 23,29 & 15,55 & 11,50 & 37,64 & 24,97 \\
\hline
\end{tabular}

Médias seguidas pela mesma letra na coluna não diferem pelo teste de Tukey $(\mathrm{p} \leq 0,05)$.

\section{DISCUSSÃO}

\subsection{Propriedades físicas dos substratos}

As propriedades físicas de um substrato são consideradas mais importantes que as propriedades químicas devido às relações entre o ar e água, que não podem ser alteradas durante a cultura, visto que após o acondicionamento do substrato nos recipientes, torna-se difícil qualquer mudança. Já as características químicas podem ser mais facilmente ajustadas posteriormente. (KRATZ et al., 2013).

A densidade volumétrica é de extrema importância para interpretar outras propriedades do substrato, tais como porosidade, espaço de aeração e disponibilidade de água (FERMINO, 2014). Além disso, o conhecimento do valor da mesma tem várias aplicações, no que se refere ao cultivo em recipientes, servindo como parâmetro para o manejo da irrigação e na análise de nutrientes (com referência à massa da amostra), a qual é indispensável para a interpretação dos laudos e recomendações práticas. (FERMINO; KÄMPF, 2012).

Fermino (2014) estabelece como referência para substratos utilizados em bandejas, valores de densidade volumétrica entre 100 e $300 \mathrm{~kg} \mathrm{~m}^{-3}$; para vasos de até $15 \mathrm{~cm}$ de altura, de 250 a $400 \mathrm{Kg} \mathrm{m}^{-3}$; vasos de 20 a $30 \mathrm{~cm}$, de 300 a
$500 \mathrm{Kg} \mathrm{m}^{-3}$; vasos maiores, de 500 a $800 \mathrm{Kg} \mathrm{m}^{-3}$. Sendo assim, os Gongocompostos do RJ e de SP, bem como o substrato

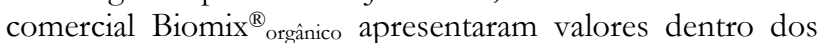
padrões aceitáveis para substratos em bandeja. Entretanto, ressalta-se que o Gongocomposto RJ apresentou menor densidade entre os três substratos. Isso pode ter ocorrido devido à natureza dos materiais utilizados no processo de gongocompostagem, bem como pelo tamanho dos péletes fecais dos gongolos, já que essas partículas são esféricas e medem cerca de $1,85 \mathrm{~mm}$, aumentando a porosidade do substrato. Já o Gongocomposto de SP é obtido por uma etapa de pré-compostagem, favorecendo uma maior taxa de decomposição dos materiais de poda urbana, aumentando sua densidade, a qual é influenciada pelas características de cada resíduo empregado no processo.

Maggioni et al. (2014) destacam que os substratos com menores densidades proporcionam maior porosidade, melhor drenagem e menor restrição física ao crescimento e desenvolvimento das plantas, corroborando com os resultados obtidos nos Gongocompostos do RJ e de SP, os quais foram menos densos e apresentaram maiores percentuais de porosidade total. A porosidade total é, de acordo com Kämpf (2005), de extrema importância para o 
crescimento das plantas, visto que a alta concentração de raízes formadas nos recipientes exige elevado fornecimento de oxigênio e rápida remoção do gás carbônico formado.

Gonçalves; Poggiani (1996) estabeleceram faixas adequadas para as características físicas dos substratos. Para a porosidade total, os autores consideram como adequados percentuais que variam entre 75 a $85 \%$. O Gongocomposto RJ e o Gongocomposto SP ficaram um pouco acima do limite estipulado ( $92 \%$ e $89 \%$, respectivamente), sendo o substrato Biomix ${ }^{\circledR}$ o único dentro da faixa especificada $(78,80 \%)$. Os resultados corroboram com os mesmos encontrados por Antunes et al. (2018), na produção de gongocompostos de diferentes tempos de obtenção e sua utilização como substrato na produção de alface em sistema orgânico. Entretanto, Carrijo et al. (2002) afirmam que os substratos utilizados no cultivo de hortaliças devem apresentar porosidade total acima de 85\%.

Quanto à microporosidade, todos os substratos orgânicos apresentaram valores acima da faixa considerada adequada (45-55\%) segundo Gonçalves; Poggiani (1996). A microporosidade é responsável pela retenção de água no substrato, que quando eleva-se consideravelmente, acaba por gerar um menor volume de substrato explorado, consequentemente há menor absorção de água e nutrientes, os quais são de extrema importância para o crescimento e desenvolvimento das mudas (MAGGIONI et al., 2014). Embora os resultados tenham ficado acima do recomendado, eles não foram capazes de influenciar negativamente o desenvolvimento das mudas.

Gonçalves; Poggiani (1996) consideram a faixa de 35$45 \%$ como sendo a adequada para macroporosidade. No entanto, todos os substratos apresentaram macroporosidade inferior a faixa proposta, apresentando de 18 a $22 \%$. Estes resultados foram inferiores aos obtidos por Antunes et al. (2019), utilizando gongocomposto como substrato de mudas de girassol ornamental, evidenciando um teor de macroporos de aproximadamente $29 \%$. Entretanto os resultados obtidos foram considerados médios pelos mesmos autores e além disso, os mesmos foram estatisticamente equivalentes, não sendo fator determinante para a diferença no desenvolvimento das mudas.

Gonçalves; Poggiani (1996) consideram como níveis adequados de capacidade de retenção de água, valores entre $20-30 \mathrm{~mL} 50 \mathrm{~cm}^{-3}$. Deste modo, os três substratos ficaram um pouco acima dos níveis adequados de retenção de água descritos por estes autores. Vale ressaltar que, como mencionado anteriormente, a retenção de água está diretamente ligada ao teor de microporos, justificando assim, a pequena acentuação nesse índice.

\subsection{Caracterização físico-química e química dos substratos}

Segundo Ludwig et al. (2014), mais importante do que os próprios teores de nutrientes do substrato, é o valor de $\mathrm{pH}$ do substrato, pois o mesmo afeta principalmente a absorção dos macronutrientes e micronutrientes. Valores de $\mathrm{pH}$ abaixo de 5,8 podem ocasionar toxicidade às plantas, já que aumenta a disponibilidade de ferro e manganês, além de reduzir a disponibilidade de nitrogênio, potássio, cálcio, magnésio e boro (STÖCKER et al., 2016), enquanto que em valores de $\mathrm{pH}$ acima de 6,5 pode-se esperar deficiências de fósforo, ferro, manganês, zinco e cobre (KRATZ et al., 2014).

Kratz; Wendling (2013) relatam que se tratando da utilização de substratos orgânicos, sem a adição de solo na sua composição, a recomendação é trabalhar com um intervalo de $\mathrm{pH}$ de 4,4 a 6,2. Todos os substratos apresentaram valores de $\mathrm{pH}$ acima do recomendado pelos autores, variando de 6,69 a 7,34. Entretanto, estes valores não foram capazes de influenciar negativamente $O$ desenvolvimento e tampouco a qualidade das mudas, corroborando com Costa (2014), o qual relata que a alface é uma espécie que tolera valores de $\mathrm{pH}$ de 6,5 a 7,5, sendo bem adaptada a solos alcalinos.

A condutividade elétrica (CE) indica a concentração de sais presentes na solução (água destilada + substrato) e nos fornece a estimativa de salinidade presente nos substratos. Segundo Minami; Salvador (2010), valores de CE acima de $3,4 \mathrm{dS} \mathrm{m}^{-1}$ são considerados muito altos para substratos, valores de 2,25 a 3,39 $\mathrm{dS} \mathrm{m}^{-1}$ são altos, valores de 1,8 a 2,24

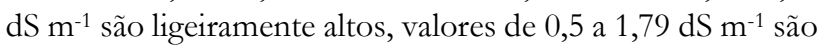
moderados, valores entre 0,15 e $0,49 \mathrm{dS}^{-1}$ são baixos e valores inferiores a $0,14 \mathrm{dS} \mathrm{m}^{-1}$ são considerados muito baixos.

Os gongocompostos apresentaram valores superiores de condutividade elétrica quando comparados ao substrato comercial Biomix ${ }^{\circledR}$ e se enquadram na faixa considerada moderada. Já o substrato Biomix ${ }^{\circledR}$ apresentou valor de CE menor, estando na categoria de baixa CE. Isso pode ter sido ocasionado pelo tempo de processamento dos resíduos utilizados na compostagem pelos gongolos, resultando em valores aceitáveis. Resultados similares foram obtidos por Antunes et al. (2019) avaliando o desenvolvimento do Helliantus annus na fase de mudas e de vaso com o uso do gongocomposto. Além disso, Antunes et al. (2018) verificou que o gongocomposto com maior tempo de compostagem apresentou um aumento na $\mathrm{CE}$, diminuição da relação $\mathrm{C} / \mathrm{N}$ e $\mathrm{C}$ orgânico, atribuída à atividade biológica presente nos péletes fecais e associativas aos gongocompostos, ocasionando a mineralização e disponibilização dos nutrientes.

A relação $\mathrm{C} / \mathrm{N}$ é um parâmetro importante na caracterização dos substratos, indicando como os materiais orgânicos se encontram no final do processo de compostagem (DA ROS et al., 2015). A instrução normativa $\mathrm{n}^{\circ} 61$ do Ministério de Agricultura, Pecuária e Abastecimento (BRASIL, 2020) destaca que a relação $\mathrm{C} / \mathrm{N}$ não pode ultrapassar a 20 e o teor de nitrogênio total deve ser no mínimo de $5,0 \mathrm{~g} \mathrm{~kg}^{-1}$ para compostos orgânicos.

O substrato Biomix ${ }^{\circledR}$ apresentou relação $\mathrm{C} / \mathrm{N}$ de 41,92, considerada alta para uma adequada mineralização dos nutrientes, podendo haver, a princípio, à imobilização do $\mathrm{N}$ mineralizado (ANTUNES et al., 2019a). No entanto, esse resultado se dá em decorrência dos componentes da sua formulação, como a casca de pinus, que possui alta relação $\mathrm{C} / \mathrm{N}$, influenciando no valor final desta relação. Os gongocompostos apresentaram valores médios de relação $\mathrm{C} / \mathrm{N}$ de 14,60 (SP) e 15,23 (RJ), demonstrando que estes se encontram estabilizados e capazes de disponibilizar os nutrientes necessários às plantas, atendendo às normas estabelecidas pelo MAPA. Essa menor relação $\mathrm{C} / \mathrm{N}$ se dá devido à natureza dos materiais utilizados no processo de compostagem e a preferência dos diplópodes por materiais mais palatáveis, sendo aqueles que tem relação $\mathrm{C} / \mathrm{N}$ mais baixas e com maiores níveis de macronutrientes como nitrogênio, fósforo, potássio e magnésio, os quais são importantes à sua nutrição, constituição e manutenção metabólica (ANTUNES et al., 2019b). 
Dias et al. (2010) afirmam que com o aumento do tempo de compostagem, ocorre diminuição do teor de matéria orgânica (MO) do composto, sendo o teor de carbono (C) um ótimo parâmetro para avaliar o grau de humificação dos compostos orgânicos. Schmitz et al. (2002) relatam que 50 a $60 \%$ da matéria orgânica é constituída por carbono e os teores ideais de carbono orgânico para substratos usados em recipientes devem ficar acima de $25 \%$, desta maneira, todos os substratos utilizados neste trabalho se enquadram, variando seus teores de 29 a 35\% (Tabela 2).

Os teores de nitrogênio presentes nos gongocompostos foram 2,5 e três vezes maiores (SP e RJ, respectivamente) quando comparado ao teor contido no substrato Biomix ${ }^{\circledR}$, o que fora capaz de proporcionar um melhor desenvolvimento das mudas de alface. Apesar de haver uma pequena diferença nos teores de $\mathrm{N}$ entre os gongocompostos $(16,65 \%$ a mais para o RJ em relação ao de $\mathrm{SP})$, os mesmos produziram mudas cujos parâmetros fitotécnicos não se diferenciaram estatisticamente entre si.

Comparando um composto orgânico processado por diplópode ( $H$. haydeniana) com outros substratos que utilizaram solo, vermicomposto e solo+esterco, Apurva et al. (2014) também observaram superioridade nutricional do gongocomposto em N, P, K, Ca e Mg. Antunes et al. (2016) também observaram o enriquecimento nutricional do gongocomposto com cálcio e magnésio, o qual fora eficaz na produção de mudas de alface cultivar Regina 2000. Segundo Foloni et al. (2013), o potássio (K) aumenta a efetividade do nitrogênio, além de ser um elemento fundamental no desenvolvimento vegetal, capaz de incrementar a translocação de carboidratos nas plantas e aprimorar a absorção de água pelas mesmas. Os resultados deste trabalho corroboram com a afirmação do autor supracitado, já que os maiores índices de massa seca de parte aérea e de raízes foram obtidos no gongocomposto RJ, que é o substrato com maiores níveis de nitrogênio $\left(23,26 \mathrm{~g} \mathrm{~kg}^{-1}\right)$ e potássio $(4,78 \mathrm{~g}$ $\left.\mathrm{kg}^{-1}\right)$.

Gonçalves; Poggiani (1996) também estabeleceram faixas de valores adequados das características químicas dos substratos, bem como níveis adequados de macronutrientes. A concentração de fósforo considerada ideal varia de 0,40 a $0,80 \mathrm{~g} \mathrm{~kg}^{-1}$, estando acima dos níveis considerados adequados nos três substratos, sendo $2,96 \mathrm{~g} \mathrm{~kg}^{-1}$ para o Gongocomposto RJ, 1,63 $\mathrm{g} \mathrm{kg}^{-1}$ para o Gongocomposto SP e 1,53 $\mathrm{g} \mathrm{kg}^{-1}$ para o substrato comercial Biomix ${ }^{\circledR}$. Para potássio considera-se adequado níveis variando de 1,17 a 3,91 $\mathrm{g} \mathrm{kg}^{-1}$, estando dentro desta faixa o Gongocomposto SP e Biomix ${ }^{\circledR}$, o Gongocomposto RJ exibiu níveis considerados altos. Os níveis de cálcio ficaram acima dos níveis considerados adequados $\left(2,00\right.$ a 4,00 $\left.\mathrm{g} \mathrm{kg}^{-1}\right)$ para os três substratos, sendo que o gongocomposto RJ apresentou valores bem acima dos recomendados, sendo de $31,69 \mathrm{~g} \mathrm{~kg}^{-1}$, o gongocomposto SP registrou 21,81 $\mathrm{g} \mathrm{kg}^{-1}$ e o Biomix ${ }^{\circledR}$ apresentou 9,03 $\mathrm{g} \mathrm{kg}^{-1} \mathrm{de}$ cálcio. Os teores de magnésio recomendados situam-se na faixa de 6,07 a 12,16 $\mathrm{g} \mathrm{kg}^{-1}$, no entanto, ficaram abaixo do recomendado para os três substratos.

Reafirma-se que apesar de ambos gongocompostos serem muito superiores em nutrientes quando comparados ao substrato comercial Biomix ${ }^{\circledR}$, existe uma diferença nutricional significativa entre ambos (Tabela 2), embora isso não tenha refletido de forma a gerar diferenças estatísticas na fase de produção de mudas. A variabilidade nos teores de nutrientes pode explicada pela diversidade e peculiaridade dos materiais utilizados no processo de gongocompostagem, que provavelmente continham mais nutrientes. Há de se considerar que, na gongocompostagem do RJ, 40\% do volume da mistura dos resíduos era composta por folhas de pata de vaca (Bauhinia sp. -espécie leguminosa), o que proporcionou a obtenção de um gongocomposto ligeiramente mais rico em nutrientes do que o Gongocomposto SP, embora ambos tenham sido eficazes na produção de mudas, cujos parâmetros seguem discutidos a seguir.

\subsection{Avaliação dos parâmetros fitotécnicos das mudas de} alface

Os gongocompostos proporcionaram a obtenção de mudas de alface com qualidade superior ao substrato comercial (Tabela 3 e Figura 3). A massa fresca da parte aérea (MFPA) das mudas oriundas do gongocomposto RJ e SP exibiram médias cujos percentuais foram de $278 \%$ e $265 \%$ maiores, respectivamente, quando comparados às médias obtidas pelas mudas produzidas com o substrato comercial Biomix ${ }^{\circledR}$. A massa seca da parte aérea (MSPA) seguiu o mesmo padrão, cujos acúmulos representaram $96 \%$ e $84 \%$ a mais que no substrato Biomix ${ }^{\circledR}$.

A massa fresca das raízes (MFR) do Gongocomposto RJ e do Gongocomposto SP foram 86\% e 67\% superiores (respectivamente) a MFR alcançada pelo substrato Biomix ${ }^{\circledR}$. A massa seca das raízes (MSR) foi $32 \%$ e $39 \%$, respectivamente, superior à média obtida pelo substrato orgânico comercial.

De acordo com Furlan et al. (2007) há melhor formação de mudas em substratos alternativos quando comparados aos substratos comerciais, obtendo maior acúmulo de massa seca da parte aérea e da raiz, corroborando com os resultados do presente trabalho.

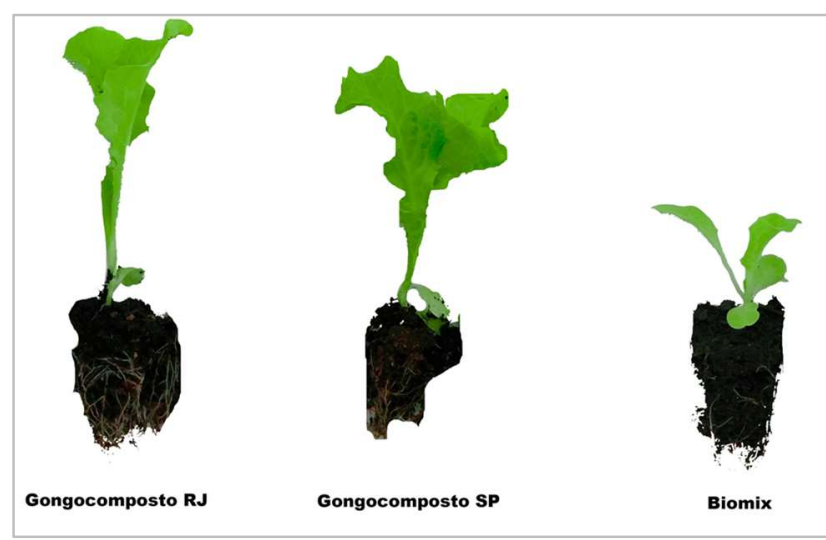

Figura 3. Mudas de alface crespa cv. Grand Rapids produzidas nos diferentes substratos orgânicos aos 30 dias após a semeadura. Figure 3. Seedlings of curly lettuce cv. Grand Rapids produced on different organic substrates 30 days after sowing.

O maior aporte de nutrientes contidos nos gongocompostos promoveu os aumentos da massa fresca e seca de parte aérea e das raízes, corroborando com os resultados obtidos por Antunes et al. (2018), que confirmaram que a qualidade das mudas de alface crespa produzida no gongocomposto e transplantadas a campo foi capaz de influenciar positivamente no desempenho agronômico da cultura.

Estes resultados reafirmam a eficiência destes substratos orgânicos quando comparados aos substratos comerciais, que nem sempre apresentam uma quantidade satisfatória de 
nutrientes necessários à fase inicial de desenvolvimento das mudas, demandando ao produtor de mudas incluir na sua rotina de trabaho a adubação de cobertura nas bandejas.

Ramanathan; Alagesan (2012) ao compararem a eficiência do vermicomposto e gongocomposto gerados aos 60 dias, oriundos de restos de flores, na produção de pimenta em vasos, obtiveram os melhores parâmetros de altura de plantas, número de folhas, área foliar, número e peso de frutos no gongocomposto. Resultados similares foram apresentados neste trabalho, onde ambos gongocompostos não apresentaram diferença estatística entre si, mas apresentaram superioridade na altura da planta, número de folhas e vigor da muda, exceto na estabilidade do torrão, onde o substrato comercial Biomix ${ }^{\circledR}$ apresentou melhor estabilidade. Esta maior estabilidade pode ser devido à natureza do material empregado na formulação do substrato, enquanto que a superioridade dos gongocompostos apresentando maiores médias em todos os demais aspectos pode ter relação indireta com o efeito hormonal que as substâncias húmicas presentes em substratos orgânicos exercem sobre as plantas, além da qualidade químicas e físicas destes substratos (CORDEIRO et al., 2010; AGUIAR, 2011; ANILKUMAR et al., 2012).

Estudos futuros deverão estar direcionados na caracterização das substâncias húmicas $(\mathrm{SH})$ contidas nestes gongocompostos, a fim de elucidar quais são as frações predominantes destas $\mathrm{SH}$ : se ácidos fúlvicos ou ácidos húmicos, e como estes agem no estímulo vegetal da alface e de outras olerícolas em fase de mudas. Ademais, há a necessidade de estudar o microbioma destes gongocompostos, pois bactérias e fungos presentes nos gongocompostos podem estar promovendo o crescimento e sanidade às mudas de hortaliças.

\section{CONCLUSÕES}

Ambos os gongocompostos apresentam propriedades físicas, físico-químicas e químicas favoráveis à sua utilização como substrato na produção de mudas de alface, cujas qualidades foram similares entre si e superiores ao substrato comercial, tido como controle.

Ademais, o gongocomposto pode ser produzido em ambientes rurais e urbanos, atendendo à necessidade atual por insumos de produção sustentáveis.

\section{REFERÊNCIAS}

AGUIAR, N. O. Características químicas e bioatividade de ácidos húmicos isolados de vermicompostos em diferentes estádios de maturação. 96f. (Dissertação de Mestrado) - Universidade Estadual do Norte Fluminense Darcy Ribeiro, Campos dos Goytacazes, 2010.

ANILKUMAR, C.; IPE, C.; BINDU, C.; CHITRA, C. R.; MATHEW, P. J.; KRISHNAN, P. N. Evaluation of millicompost versus vermicompost. Current Science, v. 103, n. 2, p. 140-143, 2012.

APURVA, P.; THAKUR, P. C.; SINHA, S. K. Caracteristics of organic compost originated from Harpaphe haydeniana (Wood) and Eisenia foetida. Internacional Journal for Exchange of knowledge, v. 1, n. 1, p. 8-11, 2014.

ANTUNES, L. F. de S.; SILVA, D. G. da; CORREIA, M. E. F.; LEAL, M. A. de A. Avaliação química de substratos orgânicos armazenados e sua eficiência na produção de mudas de alface. Revista Científica Rural, Jaboticabal, v. 21, p. 139-155, 2019a. DOI: https://doi.org/10.30945/rcr-v21i2.2680.

ANTUNES, L. F. S.; AZEVEDO, G.; CORREIA, M. E. F. Produção de mudas de girassol ornamental e seu desenvolvimento em vasos utilizando como substrato o gongocomposto. Revista Científica Rural, Jaboticabal, v. 21 , n. 2, p. 299-314, 2019. DOI: https://doi.org/10.30945/rcr-v21i2.2698

ANTUNES, L. F. S.; SCORIZA, R. N.; SILVA, D. G. da; CORREIA, M. E. F. Consumo de resíduos agrícolas e urbanos pelo diplópode Trigoniulus corallinus. Nativa, Sinop, v. 7, n. 2, p. 162-168, 2019b. DOI: http://dx.doi.org/10.31413/nativa.v7i2.6192.

ANTUNES, L. F. de S.; SCORIZA, R. N.; FRANÇA, E. M.; SILVA, D. G. da; CORREIA, M. E. F.; LEAL, M. A. de A.; ROUWS, J. R. C. Desempenho agronômico da alface crespa a partir de mudas produzidas com gongocomposto. Revista Brasileira de Agropecuária Sustentável, Viçosa, v. 8, p. 57-65, 2018. DOI: 10.21206/rbas.v8i3.3009.

ANTUNES, L. F. S.; SCORIZA, R. N.; SILVA, D. G.; CORREIA, M. E. F. Production and efficiency of organic compost generated by millipede activity. Ciência Rural, Santa Maria, v. 46, p. 815-819, 2016. DOI: http://dx.doi.org/10.1590/0103-8478cr20150714.

BARROS, P. N.; SANTOS, M. G. P.; SILVA, M. X.; CARVALHO, I. R. C.; FARFAN, S. J. A. Caracterização morfofisiológica de mudas de alface submetidas a diferentes substratos. Cadernos de Agroecologia, v. 10, n. 3, p. 1-5, 2015. Disponível em: <http://revistas.abaagroecologia.org.br/index.php/cad/article/view/18728 $>$.

BHERING, L. L. Rbio: A tool for biometric and statistical analysis using the $\mathrm{R}$ platform. Crop Breeding and Applied Biotechnology, v. 17, p. 187-190, 2017. DOI: http:// dx.doi.org/10.1590/1984-70332017v17n2s29

BRASIL. Ministério da Agricultura, Pecuária e Abastecimento - MAPA. Instrução Normativa Instrução Normativa n. 61, de 08 de julho de 2020. Regras sobre definições, exigências, especificações, garantias, tolerâncias, registro, embalagem e rotulagem dos fertilizantes orgânicos e dos biofertilizantes, destinados à agricultura. . 2020, Sec. 1.

CARRIJO, O. A.; LIZ, R. S. de; MAKISHIMA, N. Fibra da casca do coco verde como substrato agrícola. Horticultura Brasileira, Brasília, v. 20, n. 4, p. 533-535, 2002.

CORDEIRO, F. C.; FERNANDES, M. S.; SOUZA, S. R. Influência dos ácidos húmicos no metabolismo vegetal pode ser considerada uma resposta auxínica? Revista Ciências da Vida, Seropédica, v. 30, n. 2, p. 111-131, 2010.

CORREA, B. A.; PARREIRA, M. C.; MARTINS, J. D. S.; RIBEIRO, R. C.; DA SILVA, E. M. Reaproveitamento de resíduos orgânicos regionais agroindustriais da amazônia tocantina como substratos alternativos na produção de mudas de alface. Revista Brasileira de Agropecuária Sustentável, Viçosa, v. 9, n. 1, p. 97-104, 2019. DOI: $10.21206 /$ rbas.v9i1.7970.

COSTA, A. R. Nutrição Mineral de Plantas Vasculares. Escola de Ciências e Tecnologia da Universidade de Évora, Portugal. 2014. 147p.

DA ROS, C. O.; REX, F. E.; RIBEIRO, I. R.; KAFER, P. S.; RODRIGUES, A. C.; SILVA, R. F.; SOMAVILLA, L. 
Uso de Substrato Compostado na Produção de Mudas de Eucalyptus dunnii e Cordia trichotoma. Floresta e Ambiente, Seropédica, v. 22, n. 4, p. 549-558, 2015.

DIAS, B. O.; SILVA, C. A.; HIGASHIKAWA, F. S.; ROIG, A.; SÁNCHEZ-MONEDERO, M. A. Use of biochar as bulking agent for the composting of poultry manure: Effect on organic matter degradation and humification. Bioresource Technology, v. 101, p. 1239-1246, 2010.

FERMINO, M. H.; KÄMPF, A. N. Densidade de substratos dependendo dos métodos de análise e níveis de umidade. Horticultura Brasileira, Brasília, v. 30, n. 1, p. 75-79, 2012.

FERMINO, M. H. Substratos: composição, caracterização e métodos de análise. Guaíba: Agrolivros, 2014. 112p.

FILGUEIRA, F. A. R. Novo manual de olericultura: agrotecnologia moderna na produção $\mathrm{e}$ comercialização de hortaliças. Viçosa: Editora UFV, 2008. 402p.

FIORINI, C. V. A.; FERNANDES, M. D. C. D. A.; DUARTE, F. E. V. de O.; DIAS, A.; SALMI, A. P. Cultivares de alface sob manejo orgânico no inverno e na primavera na Baixada Fluminense. Revista Brasileira de Ciencias Agrárias, Recife, v. 11, n. 4, p. 335-342, 2016. DOI: DOI:10.5039/agraria.v11i4a5405.

FOLONI, J. S. S.; CORTE, A. J.; CORTE, J. R. do N.; ECHER, F. R.; TIRITAN, C. S. Adubação de cobertura na batata-doce com doses combinadas de nitrogênio e potássio. Cadernos de Agroecologia, Londrina, v. 34, n. 1 , p. 111-222, 2013. DOI: 10.5433/16790359.2013v34n117

FRANZIN, S. M.; MENEZES, N. L.; GARCIA, D. C.; SANTOS, O. S. Efeito da qualidade das sementes sobre a formação de mudas de alface. Horticultura Brasileira, Brasília, v. 23, n. 2, p. 193-197, 2005

FURLAN. F; COSTA, M.; COSTA, L. A.; MARINI, D.; CASTOLDI, G.; SOUZA, J.; PIVETTA, L. Substratos alternativos para produção de mudas de couve em sistema orgânico. Revista Brasileira de Agroecologia, v. 2, n. 2, p. 1689, 2007.

GONÇALVES, J. L. M.; POGGIANI, F. Substratos para produção de mudas florestais. In: Congresso Latino Americano de Ciência do Solo, 13., Águas de Lindóia, 1996. Resumos... Piracicaba, Sociedade Latino Americana de Ciência do Solo, 1996. CD-Rom.

GRUSZYNSKI, C. Resíduo agro-industrial “casca de tungue" como componente de substrato para plantas. 41p. (Dissertação de Mestrado) - Universidade Federal do Rio Grande do Sul, Porto Alegre, 2002.

IBGE_Instituto Brasileiro de Geografia e Estatística. Censo Agropecuário de 2017. Disponível em: https://sidra.ibge.gov.br/Tabela/6619\#resultado.

KÄMPF, A.N. Produção comercial de plantas

ornamentais. Guaíba: Agrolivros, 2005, 256pKRATZ, D.; WENDLING, I. Produção de mudas de Eucalyptus dunnii em substratos renováveis. Revista Floresta, Curitiba, v. 43, n.1, p. 125-136, 2013.

KRATZ, D.; WENDLING， I.; NOGUEIRA， A. C.; SOUZA, P. V. D. D. Propriedades físicas e químicas de substratos renováveis. Revista Árvore, Viçosa, v. 37, n. 6, p. 1103-1113, 2013. DOI: http:/ /dx.doi.org/10.1590/S0100-67622013000600012.

KRATZ, D.; NOGUEIRA, A. C.; WENDLING, I.;SOUZA, P. V. D. Substratos renováveis para produção de mudas de Mimosa scabrella. Floresta, Curitiba, v. 45, n. 2, p. 393-408, 2014. DOI: 10.5380/rf.v45i2.31249

LUDWIG, F.; FERNANDES, D. M.; GUERRERO, A. C.; VILLAS BOAS, R. L. Características dos substratos na absorção de nutrientes e na produção de gérbera de vaso. Horticultura Brasileira, Vitória da Conquista, v. 32, n. 2, p. 184-189, 2014. DOI: http:/ /dx.doi.org/10.1590/S0102-05362014000200011

MAGGIONI, M. S.; ROSA, C. B. C. J.; ROSA JUNIOR, E. J.; SILVA, E. F.; ROSA, Y. B. C. J.; SCALON, S. P. Q.; VASCONCELOS, A. A. Desenvolvimento de mudas de manjericão (Ocimum basilicum L.) em função do recipiente e do tipo e densidade de substratos. Revista Brasileira de Plantas Medicinais, Botucatu, v. 16, n. 1, p. 10-17, 2014.

MAIA, J. P. Comportamento Agronômico De Cultivares De Alface Americana Em Sistema Hidropônico. $31 \mathrm{f}$. (Dissertação de Mestrado) - Universidade Federal de Goiás, Jataí, 2019. Disponível em: <https://repositorio.bc.ufg.br/tede/bitstream/tede/94 90/5/Dissertação - João Pedro Maia - 2019.pdf>.

MILANESI, M. A. Identificação de Unidades Climáticas na Ilha de São Sebastião (SP). 305 f. (Tese de Doutorado) - Universidade de São Paulo, 2016. Disponível em:< https://www.teses.usp.br/teses/disponiveis/8/8135/td e-09062017-114749/pt-br.php>.

MILHOMENS, K. K. B.; NASCIMENTO, I. R. do; TAVARES, R. D. C.; FERREIRA, T. A.; SOUZA, M. E. Avaliação de características agronômicas de cultivares de alface sob diferentes doses de nitrogênio. Revista Verde de Agroecologia e Desenvolvimento Sustentável, Pombal, v. 10, n. 2, p. 143-148, 2015.

MINAMI, K.; SALVADOR, E. D. Substrato para plantas. Piracicaba: Editora Degaspari, 2010. 209p.

NADAI, F. B.; MENEZES, J. B. C.; CATÃO, H. C. R. M.; ADVÍNCULA, T.; COSTA, C. A. Produção de mudas de tomateiro em função de diferentes formas de propagação e substratos. Revista Agro@mbiente On-line, Boa Vista, v. 9, n. 3, p. 261-267, 2015. DOI: https://doi.org/10.18227/1982- 8470ragro.v9i3.2348.

OLIVEIRA JÚNIOR, J. F.; DELGADO, R. C.; GOIS, G.; LANNES, A.; DIAS, F. O.; SOUZA, J. C.; SOUZA, M. Análise da precipitação e sua relação com sistemas meteorológicos em seropédica, Rio de Janeiro. Floresta e Ambiente, Seropédica, v. 21, n. 2, p. 140-149, 2014.

RAMANATHAN, B.; ALAGESAN, P. Evaluation of millicompost versus vermicompost. Current Science, v. 103, p. 140-143, 1 jul. 2012.

SANTOS, M. M.; OZA, E. F.; PAIXÃO, M. V. S.; FRIZZERA JR, J. L.; ZINGUER, L.; FERREIRA, E. Resposta de plantas de pimenta dedo-de-moça em substratos comercial e orgânico com e sem adição de resíduos de carvão. Cadernos de Agroecologia, Londrina, v. 13, p. 1-6, 2018.

SCHMITZ, J. A. K.; SOUZA, P. V. D. de; KÄMPF, A. N. Propriedades químicas e físicas de substratos de origem mineral e orgânica para o cultivo de mudas em recipientes. Ciência Rural, Santa Maria, v. 32, n. 6, p. 973-944, 2002.

SENTHILKUMAR, N.; LAKHMIDEVI, R.; SUMATHI, R.; SATHISKUMAR, R.; DIVYA, G. R.; LENORA, L. M. D. Research article millicompost: an alternate biocompost for forest nurseries. International Journal 
of Current Research, v. 10, n. 6, p. 70971-70974, 2018.

Disponível

em:

http://www.journalcra.com/sites/default/files/issuepdf/31037.pdf

STÖCKER, C. M.; MONTEIRO, A. B.; SILVA, D. R. da; KUNDE, R. J.; ARAÚJO, T. B. G. Substratos alternativos para a produção de mudas de alface (Lactuca sativa L.) em sistema orgânico. Revista Da Jornada de Pós-Graduação e Pesquisa -Congrega Urcamp, Bagé, v. 13, p. 1113-1122, 2016.

TEIXEIRA, P. C.; DONAGEMA, G. K.; FONTANA, A.; TEIXEIRA, W. G. Manual de métodos de análise do solo. 3 ed. Brasília: Embrapa, 2017. 573 p. 